\title{
Conditions of appearance of the topological defects of optical indicatrix orientation in the glasses with residual stresses: Movement of the defects under application of external mechanical stress to $\mathrm{CaB}_{4} \mathrm{O}_{7}$ glasses: Errata
}

Vasylkiv Yu., Kryvyy T., Skab I. and Vlokh R.

Vlokh Institute of Physical Optics, 23 Dragomanov Street, 79005 Lviv, Ukraine, vlokh@ifo.lviv.ua

Received: 30.08 .2016

Abstract. We address the technical errors found in our recent article [Vasylkiv Yu., Kryvyy T., Skab I. and Vlokh R., 2016. Ukr. J. Phys. Opt. 17: 65-74].

Keywords: topological defects, optical indicatrix, residual stresses, glasses

PACS: $78.20 . \mathrm{hb}, 62.40 .+\mathrm{I}, 02.40 . \mathrm{Pc}$

UDC: $535.551+620.171 .5+515.143$

We have found a number of technical errors appearing in our recent article, Ref. [1]. The topological defects (TDs) in Fig. 2a and Fig. 2d should be marked as follows:
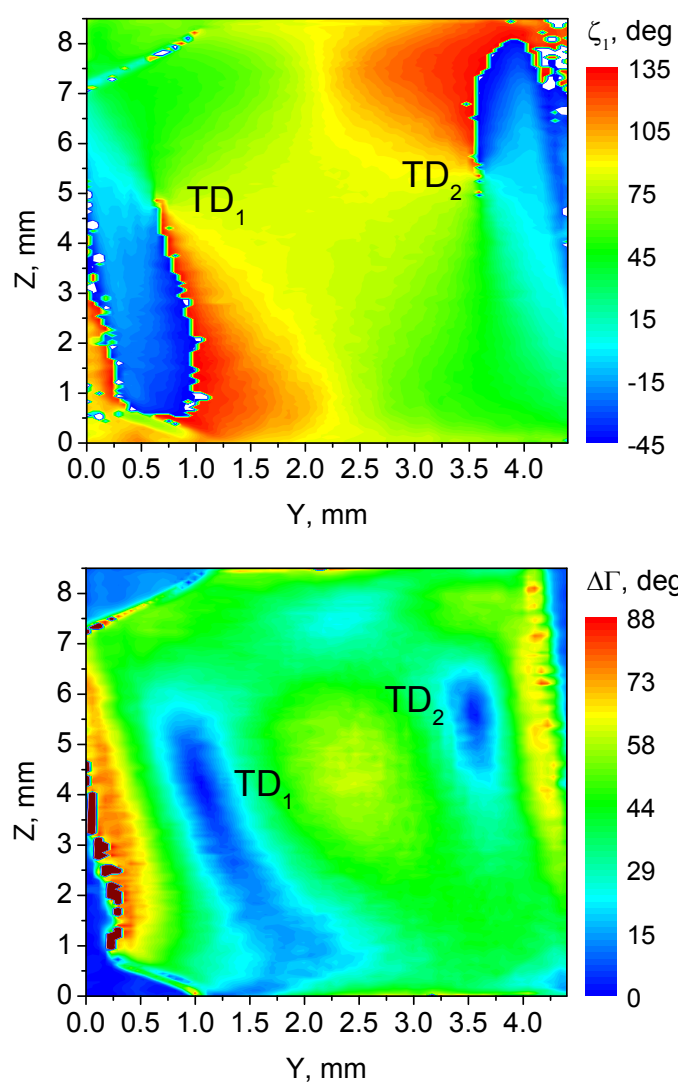

Fig 2. Spatial maps of the optical indicatrix orientation angle (a) and the phase difference (d) appearing under application of different mechanical stresses along the $Z$ axis and light propagation along the $X$ axis. The stresses applied to $\mathrm{CaB}_{4} \mathrm{O}_{7}$ glass are equal to 0 (a) and $-3.22 \times 10^{6} \mathrm{~N} / \mathrm{m}^{2}$ (d). 
The dependences of displacement of the TDs on the compressive stress in Fig. 6 should be marked as follows:

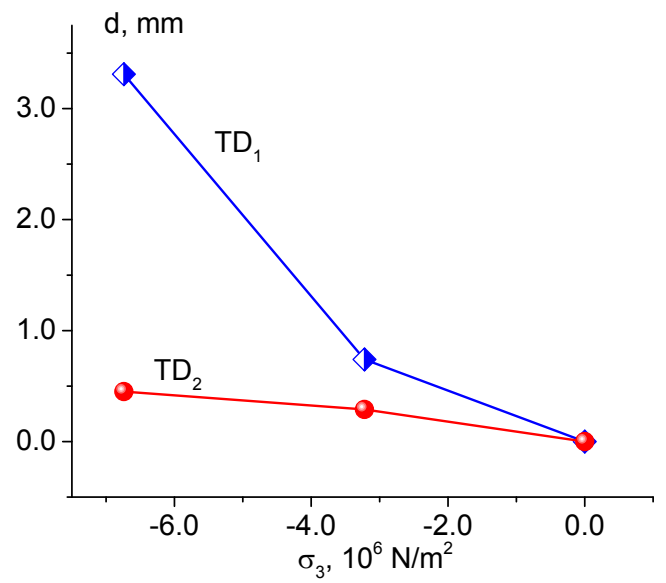

Fig. 6. Dependence of displacement of the TDs on the compressive stress, as obtained for $\mathrm{CaB}_{4} \mathrm{O}_{7}$ glass sample.

Finally, the measurement units at the ordinate axes of these dependences are millimetres (mm).

\section{References}

1. Vasylkiv Yu., Kryvyy T., Skab I. and Vlokh R. 2016. Conditions of appearance of the topological defects of optical indicatrix orientation in the glasses with residual stresses: Movement of the defects under application of external mechanical stress to $\mathrm{CaB}_{4} \mathrm{O}_{7}$ glasses. Ukr. J. Phys. Opt. 17: 65-74.

Vasylkiv Yu., Kryvyy T., Skab I. and Vlokh R. 2016. Conditions of appearance of the topological defects of optical indicatrix orientation in the glasses with residual stresses: Movement of the defects under application of external mechanical stress to $\mathrm{CaB}_{4} \mathrm{O}_{7}$ glasses: Errata. Ukr.J.Phys.Opt. 17: $167-168$

Анотація. Виправлено технічні помилки, виявлені в нашій недавній роботі [Vasylkiv Yu., Kryvyy T., Skab I. and Vlokh R., 2016. Ukr. J. Phys. Opt. 17: 65-74]. 